A 20 year old male attended the accident and emergency department with a six hour history of increasing agitation and hyperactivity, associated with feelings of impending death and visual hallucinations. Fourteen hours previously he had swallowed four whole nutmegs and half a litre of vodka for a "buzz". Five hours after ingestion he experienced a tingling feeling in his hands and feet, which later spread to his whole body. He felt "detached from the world" and stated that everything appeared to move in slow motion. He subsequently experienced dry mouth, thirst, nausea, palpitations, and dizziness. This progressed to the state of high agitation in which he presented.

Physical examination revealed a flushed, agitated young man, fully orientated, with a tachycardia of $130 /$ minute, blood pressure of $120 / 85 \mathrm{~mm} \mathrm{Hg}$, and a respiratory rate of 24/minute. He was apyrexial. Pupils were dilated (size 4), reacting briskly to light and accommodation. Neurological examination revealed hyper-reflexic upper and lower limbs. The remainder of the physical examination was normal.

Electrocardiography revealed a sinus tachycardia and laboratory investigations were normal. He was admitted for observation. His altered mental state persisted for 18 hours after admission ( 32 hours after ingestion) and the sinus tachycardia resolved after 20 hours. $\mathrm{He}$ was discharged 36 hours after admission, with psychiatric follow up arranged.

The spice nutmeg has long been used for purposes other than culinary. Not least among these is its use as a recreational drug, based on its purported euphoric and hallucinogenic properties.

Nutmeg's use in this context stems from the Crusades, and it has also been a well documented substance of abuse among prison inmates. ${ }^{1}$ Nutmeg ingestion gained currency during the $60 \mathrm{~s}$ and $70 \mathrm{~s}$, when it was touted as a cheap alternative to alcohol and other mind altering substances. Most of the published case reports date from this time, and describe toxic effects similar to our case. ${ }^{2}$ The clinical course is generally benign and management is largely supportive, although cases complicated by hypotension, cyanosis, acidosis, coma and, in one instance, death have been reported. Hypertension can be treated with phentolamine, but sedatives should be used with caution as they may cause alternating drowsiness and delirium (information from the National Poisons Information Centre, Beaumont Hospital, Dublin, Ireland). Nutmeg comprises $5-15 \%$ volatile oils, of which myristicin is the largest fraction. Myristicin is metabolised to 3-methoxy-4,5 methylenedioxy-amphetamine (MMDA), a psychoactive sympathomimetic. It is postulated that this accounts for most of nutmeg's toxic effects.

While historically nutmeg appears to have enjoyed a reputation as a hallucinogen, in circumstances where the spice is taken in excess, a typical and unpleasant clinical syndrome ensues. This, presumably, is why nutmeg abuse is virtually unheard of nowadays, with teenagers more likely to encounter it at the dinner table than on the street corner.

G I QUIN

N F FANNING P K PLUNKETT

Accident and Emergency Department, St Fames's Hospital, Dublin 8, Ireland (Correspondence to: Dr Gareth Quin, Royal Gwent Hospital, Newport, Gwent NP9 2UB)
1 Schulze RG. Nutmeg as an hallucinogen. N Engl J Med 1976;294:849.

2 Payne RB. Nutmeg intoxication. N Engl J Med 1963;269:36-8.

\section{CS spray}

EDITOR,-Breakwell and Bodiwala's article on the consequences for an accident and emergency (A\&E) department of CS spray exposure is timely. ${ }^{1}$ In 1996 the police service in England and Wales carried out a six month trial of CS aerosol incapacitant in selected forces. $^{2}$

Police surgeons were involved in submitting reports where consent was given on the medical condition of those sprayed. Due to the involvement of the members the Association of Police Surgeons produced an information sheet Crowd Control Agents: Clinical Effects and Management. ${ }^{3}$

In August 1996 the Home Secretary announced his support for any chief officers of police wishing to issue CS to officers on the beat. Within the London area police officers are now being trained and the incidents of exposure are likely to increase.

A person arrested who has been sprayed with CS incapacitant spray will be examined by a forensic medical examiner (police surgeon) as soon as possible. However members of the public who may be involved are likely to present themselves to $A \& E$ departments for advice. It is most important therefore that $A \& E$ staff are prepared to deal with the clinical effects of crowd control agents.

MARGARET M STARK Education and Research Sub-Committee, Association of Police Surgeons,

"Dubolly", 20 Sandy Lane,

Cheam, Surrey SM2 7NR

1 Breakwell A, Bodiwala GG. CS gas exposure in a crowded night club: the consequences for an accident and emergency department. J Accid Emerg Med 1998;15:56-7.

2 Kock E, Rix B. A review of police trials of the CS aerosol incapacitant. Police Research Group: police research series paper 21 . London: Home Office, 1996.

3 Association of Police Surgeons. Crowd control agents: clinical effects and management. Harrogate: APS, July 1996.

\section{"Shop hopping"}

EDITOR,-Napoleon called us a nation of shop keepers. We are now, I believe, a nation of shoppers. Some people shop unfunded. We call then shoplifters. They rely on a combination of stealth, speed, and occasional force. Here are two cases of a variant of shoplifting that I call "shop hopping". A shop hopper is an individual with a habit of regularly faking collapse in shops to avoid payment.

\section{Case reports}

CASE 1

Elizabeth presented to our accident and emergency department at the Derbyshire Royal Infirmary in 1979. She had no general practitioner. She had a respiratory tract infection. She received antibiotics and soon recovered. She then was brought to our hospital practically every few days by the ambulance service for the next four years. The story was always the same. She "collapsed" with her shopping at the checkout of a food store. An ambulance was called. Well meaning shoppers put her shopping in the ambulance too-all unpaid for. Once in our department, she usually recovered quite quickly and walked home. She lived nearby and rarely stayed long enough to be examined. No medical cause was ever found for these timely attacks. She became well known to all the emergency crews on the ambulances and was also well known to our staff. One of our sisters even shouted to her to "get up and get out" in Sainsburys. It worked that time but did not cure the habit. (The sister was nearly lynched.) The last time I saw Elizabeth she had collapsed with a stroke; she died soon after.

CASE 2

Patricia presented to our department recently with chronic back pain demanding analgesia. She had just come from Scotland and already had had a row with a general practitioner locally. She then expressed suicidal intent and was referred to a psychiatrist. Telephone calls to other hospitals confirmed her to be a "hospital hopper". However, the ambulance services of several counties knew her better as "the lady who collapsed in food stores at the check out". She then obtained free food as they conveyed her in comfort to the local hospital; this happened many times. She had come south on a shop and hospital hopping spree!

These two cases illustrate the habits of a "shop hopper". Neither patients had a good relationship with a general practitioner. These patients are a type of "hospital hopper", who purposely abuse the ambulance and hospital services for their gain. We, the taxpayers, foot the bill. Circulating pictures of such patients to shops would breach medical etiquette. Challenging such patients in a store does not cure them. The store cannot send a bill to the patient as the goods have not been through the till. The ambulance service cannot "boycott" these people as they have a duty to convey collapsed patients to a hospital. We doctors have a duty to examine all such patients. Such a collapse may be genuine. Once in a hospital, recovery is rapid, and they take their own discharge prior to the police arriving. Shops, hospitals, and the police need to recognise these people and become more vigilant. I cannot think of a better way to shop!

$$
\begin{array}{r}
\text { A FRASER-MOODIE } \\
\text { Emergency Department, } \\
\text { Derbyshire Royal Infirmary NHS Trust, } \\
\text { London Road, Derby DE1 } 2 Q Y
\end{array}
$$

\section{The Faculty of Accident and Emergency Medicine}

\section{Panel of Examiners}

Applications are invited from consultants in accident and emergency medicine who have been in post for at least five years and who wish to be appointed to the Panel of Examiners.

The examination for the Exit Diploma of the FFAEM is currently held twice a year at various venues in the UK.

The closing date for receipt of applications is 1 September 1998.

Further details and an application form are available from: The Faculty of Accident and Emergency Medicine, 35-43 Lincoln's Inn Fields, London WC2A 3PN (tel: 01714057071 ). 